\title{
Hippuric Acid
}

National Cancer Institute

\section{Source}

National Cancer Institute. Hippuric Acid. NCI Thesaurus. Code C87277.

An acyl glycine produced by the conjug ation of benzoic acid and glycine, found as a

normal component in urine as a metabolite of aromatic compounds from food.

Increased urine hippuric acid content may have antibacterial effects. 